Viso - Cadernos de estética aplicada Revista eletrônica de estética

ISSN 1981-4062

No 19, jul-dez/2016

http://www.revistaviso.com.br/
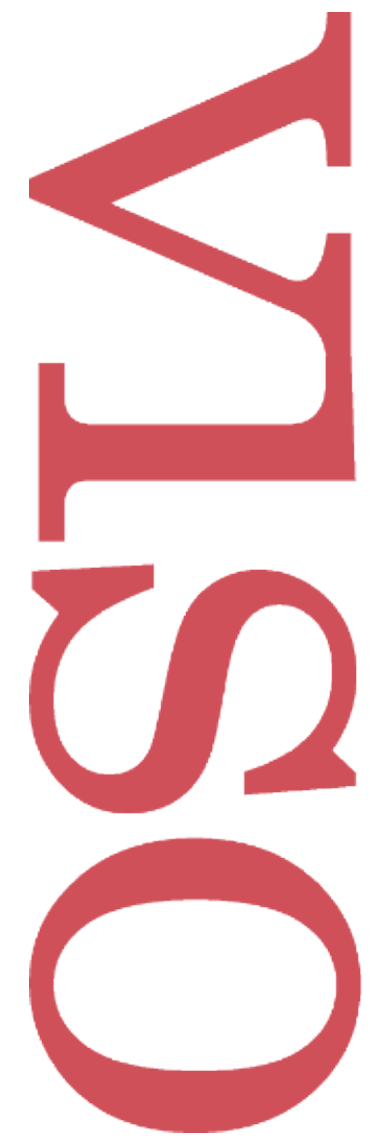

\title{
Watteau e a irrupção da pintura moderna na França do século XVIII \\ Vinicius Figueiredo
}

Universidade Federal do Paraná (UFPR)

Curitiba, Brasil 


\section{RESUMO}

Watteau e a irrupção da pintura moderna na França do século XVIII Antoine Watteau, conhecido como pintor das "fêtes galantes", foi usualmente considerado um partidário poético da superfície, dos divertimentos e da frivolidade. Argumento nesse texto que por meio dessas opções poéticas, ele descobriu a dimensão dramática da vida moderna na França setecentista.

Palavras-chave: Watteau - rococó - fête galante - vida moderna

\section{ABSTRACT}

\section{Watteau and the Birth of Modern Painting in XVIIIth Century France}

Antoine Watteau, known as the painter of the "fêtes galantes", was considered a poetical partisan of the superficial, pleasant and frivolous life. I argue in this paper that through these poetical options he found out the dramatical dimension of modern life in Eighteenth century France.

Keywords: Watteau - rococo style - fête galante - modern life 


\section{FIGUEIREDO, V. "Watteau e a irrupção da pintura moderna na França do século XVIII". In: Viso: Cadernos de estética aplicada, v. X, n. 19 (jul-dez/2016), pp. 178-197.}

DOI: 10.22409/1981-4062/v19i/239

Aprovado: 08.11.2016. Publicado: 28.12.2016.

(C) 2016 Vinicius Figueiredo. Esse documento é distribuído nos termos da licença Creative Commons Atribuição-NãoComercial 4.0 Internacional (CC-BY-NC), que permite, exceto para fins comerciais, copiar e redistribuir o material em qualquer formato ou meio, bem como remixá-lo, transformá-lo ou criar a partir dele, desde que seja dado o devido crédito e indicada a licença sob a qual ele foi originalmente publicado.

Licença: http://creativecommons.org/licenses/by-nc/4.0/deed.pt_BR

Accepted: 08.11.2016. Published: 28.12.2016.

(C) 2016 Vinicius Figueiredo. This document is distributed under the terms of a Creative Commons Attribution-NonCommercial 4.0 International license (CC-BY-NC) which allows, except for commercial purposes, to copy and redistribute the material in any medium or format and to remix, transform, and build upon the material, provided the original work is properly cited and states its license.

License: http://creativecommons.org/licenses/by-nc/4.0/ 
O ingresso de Antoine Watteau (1684-1721) na Academia Real de Pintura e Escultura deu-se em 27 de agosto de 1717, cinco anos após ter sido recrutado para integrá-la por Antoine Coypel e quinze anos após ter deixado Valenciennes por Paris pela primeira vez. Seu morceau de réception, a célebre "Peregrinação à ilha de Cítara", representa casais de cortesãos prestes a embarcar, não se sabe se para a ilha ou em retorno para o continente, cada qual absorto com seu par, numa espécie de coreografia que evoca retiro, gracejo, passatempo e, como já foi observado ${ }^{1}$, certa melancolia.

A história da recepção desse quadro é atribulada. Watteau demorou cinco anos para finalizá-lo e não quis ou não conseguiu realizar uma composição elevada, como de praxe se fazia para ser acolhido na Academia. Além disso, o quadro terminou recebendo, ninguém sabe ao certo por parte de quem, o título de "une fête galante". Na esteira desse episódio, difundiu-se no curso do século XVIII e sobretudo no século XIX a versão de que Watteau teria sido acolhido na Academia como "peintre des fêtes galantes", coisa que jamais aconteceu. ${ }^{2}$ De todo modo, o nome de Watteau associou-se à expressão "fête galante" e, embora sua pintura inclua também muitas cenas de commedia dell'arte e retratos da vida militar, não é despropositado iniciar nosso estudo assinalando o campo semântico dessa expressão: fazê-lo será ocasião para identificar semelhanças e rupturas do "gosto de Watteau" com o clima poético e moral da segunda metade do século XVII na França.

O adjetivo "galante" era corrente na língua francesa no século XVII e havia ganho particular evidência no campo da cultura, quando passou a qualificar um conjunto de obras romanescas surgidas entre o fim da década de 1650 e 1660, com autores como Segrais (Nouvelles françaises ou les Divertissements de la Princesse Aurélie, 1657) e Mme. de La Fayette (La Princesse de Montpensier, 1662; La Princesse de Clèves, 1678), dentre outros. Classificadas pela crítica do período como "des nouvelles ou des historiettes" (Sorel, De la connaissance de bons livres, 1671) ou como "petites histoires" por oposição aos "grands romans" (Du Plaisir, Sentiments sur l'histoire, 1683), essas obras, também chamadas "nouvelles galantes", se contrapunham ao romance heróico, representado por autores como Honoré d'Urfé, Gomberville, Mlle. de Scudéry e La Calprenède, e que gozara de grande prestígio até meados do século XVII. Com a aparição das narrativas mais breves e fortemente engajadas com a verossimilhança de Segrais e Mme. de La Fayette, assiste-se a uma verdadeira inflexão da forma romanesca na França, rumo à acepção moderna do romance. $\mathrm{O}$ abade de Charnes resume o ponto da seguinte maneira: 
[as histórias galantes] são cópias simples e fiéis da verdadeira História, geralmente tão verossímeis, que as tomamos pela própria História. São ações particulares de pessoas privadas ou consideradas em uma condição privada que são desenvolvidas e expostas à vista do público em uma sequência natural, cercadas por circunstâncias agradáveis, e que ganham a credulidade com tal facilidade, que se pode frequentemente considerar as ações que elas contêm como as fontes secretas dos eventos memoráveis que nos foram ensinados pela História [...]. ${ }^{3}$

Como se vê, a verossimilhança da "nouvelle" ou "histoire galante" é atingida na medida em que o autor retrata ações particulares de pessoas privadas ou "consideradas em um estado privado", isto é, pessoas públicas visadas em sua intimidade e seu "natural". Esse aspecto, que constitui marca comum a quase todos os romances de Mme. de La Fayette, possui uma implicação moral importante. A História, até ali considerada o produto da ação desejada dos grandes homens, revela-se, nessas narrativas, o resultado menos heroico e mais fortuito, arbitrário, das paixões humanas, que animam tanto os grandes, quanto o comum dos homens. ${ }^{4}$ Sob esse aspecto, a aparição da nova forma romanesca revela seu alinhamento com o pensamento moral de B. Pascal, cuja distinção entre "grandezas naturais" e as "grandezas de estabelecimento" ${ }^{5}$ já sustentava o caráter arbitrário e convencional das diferenças de ordem social existentes entre os indivíduos. ${ }^{6}$ Em consonância com isso, a nouvelle galante subverte o romance heroico, humanizando seus protagonistas a ponto de lhes deixar como única alternativa para evitar a desordem passional a "liberdade de indiferença", isto é, a definitiva renúncia aos afetos e às paixões (como dá exemplo a princesa de Clèves, dentre outras protagonistas de Mme. de La Fayette). Essa humanização não corresponde, bem entendido, à descoberta de uma verdade; trata-se de uma invenção moral e psicológica, cuja forma ficcional privilegiada corresponde à "nouvelle galante". Voltando ao nosso ponto inicial, portanto: no período entre 1660 e 1690, nosso adjetivo assinala, juntamente com outros tantos indícios, a ruptura da cultura francesa com a moral heroica que, durante a primeira metade do século XVII, animara a moral, a psicologia, a dramaturgia e a política na França.

\section{III}

O que resta dessa experiência da nouvelle gallante na poética de Watteau? Dito de outra maneira, de que significado moral torna-se portador o adjetivo "galante", quando, a partir de Watteau, passa a qualificar os divertimentos da alta sociedade parisiense? Martin Eidelberg também chama a atenção para o fato de que os dicionários de arte do século XVIII recorrem menos à expressão "fête galante" do que a "sujet galant", como atesta este comentário de Antoine La Roque: "O gênio desse hábil artista o fazia compor pequenos temas galantes: casamentos campestres, bailes, mascaradas, festas marinhas, etc" ${ }^{7}$ Watteau é aqui caracterizado através de sua preferência temática pelo que é "pequeno" e "galante", ou melhor: por "pequenos temas galantes". A crer em La Roque, portanto, o "gosto de Watteau" (a expressão se difunde no curso do século) se 
opõe ao modelo da virtude heroica, a começar porque o heroísmo característico de Corneille ou Poussin simplesmente não cabe numa escala reduzida, como aquela em que Watteau situa seus temas. Sob esse aspecto, poder-se-ia indagar, Watteau não segue a via aberta pela "petite nouvelle", que também já havia posto em xeque a elevação dos indivíduos típica do modelo heroico de virtude?

Responder a essa questão requer levar em conta, primeiro, que há diferentes modos de opor-se à ideia do herói clássico, isto é, de opor-se à convicção clássica, conforme a qual os indivíduos se diferenciam entre si pelo uso que dão a suas paixões. A "nouvelle galante", por exemplo, subverte essa premissa comum à moral cartesiana e à dramaturgia cornelliana nivelando todos os indivíduos sob a condição de agentes expostos ao furor das paixões. Se é verdade que "apenas o humor e o amor-próprio guiam os homens", como sentencia La Rochefoucauld (que, como se sabe, colaborou com Mme. de La Fayette na redação de alguns de seus romances), nesse caso, o ideal de generosidade, exposto no Tratado das paixões (1649), assim como a afirmação do valor de si, como exemplificado por Rodrigo e Ximena no Cid (1637), aparecerão como outras tantas expressões do amor próprio.

Por aí já se vê o traço que une a "nouvelle galante" não apenas às reflexões morais de Pascal, como também às máximas de La Rochefoucauld. Quer através do romance ou da forma sentencial, trata-se de apontar para a incapacidade dos indivíduos em diferenciarem-se uns dos outros. Levada ao extremo, essa indistinção originária (que Pascal articula com a doutrina do pecado original) destitui os homens de suas características individuais; eles se tornam portadores de paixões que assumem completamente o governo de sua pessoa. Mas isso, convém sublinhar, é retratado em regime de elevação; não por acaso, essa mesma convicção admite a expressão trágica característica da poesia de Racine. Também a narrativa da "nouvelle galante" transcorre em regime elevado - já que a única alternativa ao desgoverno das paixões é sua recusa em bloco, em nome da "liberdade de indiferença" (eis o que faz, dentre outros heróis em negativo, a princesa de Clèves).

Em Watteau, a escolha pelos "pequenos temas galantes" também segue na direção da recusa do modelo da virtude clássica. Mas, agora, o reconhecimento da incapacidade dos indivíduos em permanecem agentes morais em sentido estrito (o que suporia, tudo somado, a eficácia da vontade em concurso com o entendimento sobre o universo passional) não engendra a representação elevada de sua queda no solo inimigo da "humanidade", no seio da qual nos reconhecemos todos iguais. O universo habitado pelos casais retratados por Watteau nas "fêtes galantes" é, em primeiro lugar, superficial; e se trata de uma superfície unidimensional, desprovida de uma profundidade subjacente por referência à qual se pudesse instituir o contraste entre moralidades desiguais (o alto e o baixo, a origem e a atualidade, etc.). Isso é o que basta para desengajar a mimesis com qualquer forma de elevação, mesmo se pelo avesso, como ocorre em diferentes variantes da cultura francesa no período entre 1660 e 1690. Sob esse aspecto, a 
"nouvelle galante" pertence a outro tempo que ao das "fêtes galantes" ou dos "petits sujets galantes" que iriam consagrar o "gosto de Watteau" na primeira metade do século seguinte. Como a moral pascaliana ou a tragédia de Racine, a "nouvelle galante" encontra sua correspondência plástica em uma pintura que imita em regime elevado o desgoverno dos homens, causado, em última análise, pelo fato de que cada um deles, mostrando-se incapaz de reflexão, se reduziu a personificar esta ou aquela paixão. É disso que dá exemplo, entre outros casos, o célebre quadro de Charles Le Brun, As rainhas da Pérsia diante de Alexandre.

\section{IV}

Vejamos mais de perto os parâmetros sob os quais Watteau desenvolve seu princípio dramático, paradoxalmente ligado, como sugerimos, à conviç̧ão de que os homens habitam uma superficialidade sem fundo, sem história e, no limte, sem sentido - o que possivelmente explica por que, como veremos adiante, sua pintura tenha sido considerada frívola ou gratuita por parte de seus contemporâneos. A fim de fazer esse comentário atendo-se aos aspectos formais dessa novidade, convém voltarmos nossa atenção para a categoria de composição, essencial na crítica e na prática pictórica do período.

Comecemos observando que, de uma maneira ou de outra, e a despeito de diferenças poéticas decisivas existentes entre $\mathrm{N}$. Poussin e seus sucessores da segunda metade do século, como, por exemplo, Charles Le Brun, a pintura francesa seiscentista permaneceu marcada pela reflexão teórica da tradição classicizante, que convergiu para a fundação da Academia Real de Pintura e Escultura, em 1648. Nesse quadro, o que mais salta à vista é a relevância outorgada à teoria dos gêneros pictóricos, inspirada na divisão aristotélica dos gêneros literários. Veja-se a redação dessa ideia por André Félibien (1619-1695):

Assim aquele que faz excelentemente paisagens está acima de um outro, que somente
faz frutas, flores ou conchas. Aquele que pinta animais viventes é mais estimável do que
os que representam apenas coisas mortas e sem movimento; e como a figura do
homem é a mais perfeita obra de Deus sobre a terra, é igualmente certo que aquele que
se torna imitador de Deus, pintando figuras humanas, é muito mais excelente que todos
os demais... Não obstante, um pintor que só faça retratos ainda não atingiu essa alta
perfeição da arte e não pode pretender à honra que recebem os mais sábios. Para
tanto, é preciso passar de uma única figura para a representação de várias em conjunto;
é preciso abordar a história e a fábula; é preciso representar as grandes ações como os
Historiadores ou temas agradáveis, como os Poetas. ${ }^{8}$ A hierarquia entre os pintores ordena-se conforme o assunto que imitam: quem pintar homens é mais excelente do que quem pintar animais ou "coisas mortas". Para atingir a excelência máxima, não basta retratar homens e mulheres - é preciso, além disso, representar as figuras em conjunto, entenda-se, dominar a composição dos elementos 
imitados, de modo a construir uma narrativa e, assim, "abordar a história e a fábula". Por onde se vê que a afirmação do privilégio da pintura histórica diante dos outros gêneros liga-se, no passo de Félibien, com a aceitação prévia da validade do lema ut pictura poesia. É por constituir narrativa que a pintura histórica dá o que pensar; é nessa medida que ela é superior à imitação "mecânica" da vida. O apreço em relação à pintura histórica é suficientemente consensual, a ponto de um autor como Roger de Pilles, que se opôs em vida a Félibien, convergir inteiramente com ele nesse ponto:

Os pintores servem-se com razão da palavra história para significar o gênero de pintura mais considerável, e que consiste em colocar juntas várias figuras, e se diz: este pintor faz a história, esse outro, animais, aquele, a paisagem, um quarto, flores, e assim por diante. ${ }^{9}$

Quer na representação de um grande feito, quer de uma biografia consagrada, a pintura histórica permanece elevada. $\mathrm{O}$ descaso em imitar a realidade prosaica e a valorização da representação do grande indivíduo exprime-se, no plano formal, na unificação da composição em torno do feito, da história ou da exemplaridade do grande homem, cuja apresentação solicita elevação ${ }^{10}$, como se vê no quadro de Le Brun, Chanceler Séguier à recepção de Luís XIV em Paris, de 1655-1661 ou na Apoteose de Luís XIV, de 1677, na qual Luís XIV ocupa o centro da cena, em torno do qual transcorre a ação. Em contraste com isso, a relação entre abordagem moral e composição pictórica é entabulada por Watteau de modo inédito. Se, em Poussin, os personagens são apresentados como suporte consciente da narrativa; se, no quadro de Le Brun sobre as rainhas da Pérsia, cada uma delas personifica diferentes paixões, numa economia política cujo princípio não coincide com nenhum indivíduo em particular; em Watteau, em contrapartida, o alcance ordenador que a composição possui para a narrativa é completamente negligenciado.

Isso está ligado, bem entendido, ao fato de ele inscrever-se na tradição da pintura de gênero, cara à pintura holandesa do século XVII. Muito embora, como observamos, sua recepção na Academia real tenha prescindido de toda qualificação determinada (a ideia de tornar a "fête galante" um gênero só aparece com o ingresso de Pater na instituição, em $1728^{11}$ ), a crítica contemporânea não se enganou ao associá-lo às "bombachadas". ${ }^{12}$ Há, de fato, parentesco e filiação consciente de Watteau a essa tradição. Assimilação essa que, convém notar, motivou desde cedo certo descaso da crítica em relação à sua pintura. É o que atestam, entre outros fatores, as objeções que lhe dirige seu amigo e protetor, o Conde de Caylus, na conferência que apresentou à Academia real de pintura e escultura em 1748. Comentando o uso arbitrário que nosso pintor fazia de suas figuras, escolhidas conforme se prestavam para o fundo que havia trabalhado, Caylus arremata com as seguintes ponderações:

Esse modo de compor, que seguramente não deve ser seguido, é a verdadeira causa dessa uniformidade que se pode reprovar aos quadros de Watteau. Independentemente do fato de que, inadvertidamente, ele repetia com muita frequência a mesma figura, 
fosse porque ela Ihe apetecia, fosse porque, praticando, era a primeira figura que se lhe apresentava. É ainda isso o que investe as estampas gravadas por ele [gravées d'après lui] uma espécie de monotonia e de relação geral que não admitem em nenhuma hipótese a quantidade. Em resumo, à exceção de alguns dentre seus quadros, tais como o Accordée ou la noce de village, o Bal, o Enseigne faite pour le sieur Gersaint, o Embarquement de Cythère, que pintou para sua recepção em vossa Academia e que repetiu, suas composições não possuem nenhum objeto. Não exprimem o concurso de qualquer paixão e são desprovidas de um dos ingredientes mais picantes da pintura, a saber, a ação. Apenas ela, como sabeis os Senhores, pode comunicar a vossa composição, em especial no Heróico, este fogo sublime que fala ao espírito, o atinge, o envolve e o enche de admiração. ${ }^{13}$

O juízo de Caylus conforme o qual as composições de Watteau não possuem objeto algum só é válido se nos ativermos à significação convencional, classicizante, de "objeto" pictórico. Isentos desse compromisso, estamos livres para investigar a hipótese de que a prática de um repertório rebaixado teria possibilitado a Watteau captar aspectos essenciais do indivíduo moderno, irredutíveis à elevação heroica e à composição de viés unificante próprias da Grande Maneira. Dito de outro modo, caberá investigar se, ao negligenciar a convenção conforme a qual só é objeto da pintura o que pertence à História, Watteau não terminou atingindo, não apenas o aspecto mundano e prosaico da vida parisiense do início do século XVIII, como também, e através disso, a imitação do indivíduo atravessado pelo isolamento, pela transitoriedade da vida e, pelas mesmas razões, impossibilitado de encontrar lugar na escala elevada do herói clássico ou de seu reverso trágico, este último exemplificado pela queda de Fédra ou de Hipólito, de Racine, isso para não mencionar o caso das rainhas da Pérsia, de Le Brun.

\section{V}

Dadas as prerrogativas da teoria dos gêneros e da concepção classicizante da compositio, a transição de uma mimesis elevada para a representação de temas cotidianos, destituídos de uma narrativa eloquente, só poderia aparecer sob a rubrica de uma pintura menor, como a pintura de gênero, quando não associada à representação das bombachadas. É exato dizer que Watteau pinta o que é "menor": são os "pequenos temas galantes", de que dá notícia La Roque em 1721, como já tivemos ocasião de mencionar. À primeira vista, a poética de Watteau adere totalmente à jovialidade da vida cotidiana de cortesãos e burgueses médios ou de camadas altas, retratados em momentos de ócio, lassidão ou devaneio, envoltos em uma narrativa avessa a toda e qualquer teleologia. Na maioria das composições, a ação transcorre em mais de um plano. Embora também haja interação entre as personagens, elas parecem irrelevantes ${ }^{14}$, se comparadas ao que se vê na composição histórica. Em relação à pintura clássica, percebe-se um nítido rebaixamento narrativo, aferível seja pela matéria, seja pela forma da imitação. Cenas nas quais homens cortejam damas, soldados repousam, atores da commedia dell'arte figuram no palco ou fora dele, abandonados à sua existência momentânea e passageira, admitem uma composição segmentada e, 
portanto, isenta de todo compromisso com o empuxo procurado pela pintura histórica. E já se pode adivinhar em que medida essa diferença concerne aos aspectos morais aos quais aludimos ao apresentar o significado do adjetivo "galante", presente de partida nas obras literárias.

Considere-se, sob essa ótica, o quadro de recepção feito por Watteau para a Academia, a "Peregrinação à ilha de Cítara". Não há, exatamente, centro narrativo; Watteau parece pintar uma atmosfera, que envolve casais no momento em que se preparam para ir ou retornar da ilha de Cítara, o paraíso mitológico dos amantes. Eis o que afirma sobre a cena M. Levey:

Encerrou-se um dia de festa. A estátua de Vênus foi coberta de seu tributo de rosas e quando a noite se aproxima os relutantes amantes-pelegrinos devem deixar a ilha. $\mathrm{A}$ ideia da passagem de tempo, o inevitável movimento da vida, é transmitida pelo movimento da composição: desembaraçando-se da passividade pétrea da estátua pólo fixo em meio à fluidez - pelos três pares de amantes que representam um despertar gradual para a realidade, até o grupo animado que entra no barco em meio a uma revoada de cicerones. [...]. Uma realidade agridoce subjaz a todos os ornamentos serenos da roupagem alegórica e fantasiosa. Entretanto, o quadro escapa à categoria de gênero, tal como evita ser mitológico. Sua preocupação central é com a humanidade - na qual permanece típico de seu século. ${ }^{15}$

Acrescentaríamos que essa humanidade é retratada de maneira não edificante, o que projeta a poética de Watteau em duas direções complementares - a fragilidade e a dissipação. Ambas são reforçadas pela ausência de unidade compositiva que estruture a ação. Se a poética de Watteau se aproxima mais de Turner do que de Poussin, isso provavelmente se explica pelo fato de que ambos pintam mais "atmosferas" do que narrativas com início, meio e fim; as ações e paixões imitadas veem-se assim destituídas de toda expressão heróica e rebaixadas ao plano da intimidade dos pequenos gestos, daquilo que Pascal situara no horizonte do divertimento, com toda a ambiguidade que já havia conferido ao tema.

É isso o que também se percebe em "A perspectiva", de 1717/1718. Tudo faz crer que a edificação ao fundo seja a fachada de jardim da casa construída para Le Brun e que terminou sendo adquirida por Pierre Crozat em 1702, onde Watteau se hospedou regularmente em suas estadias em Paris. O esquema compositivo é semelhante ao utilizado em "Peregrinação à ilha de Cítara", pois também aqui a matéria da da mimesis corresponde à captura instantânea da vida. Daí porque a "ação" seja segmentada através da distribuição de casais que se entretêm em um universo próprio, irredutível a toda teleologia. Na direção da emancipação das personagens da narrativa heróica, Watteau, em quadros como "Pierrot contente" (c. 1712 ), se dá a liberdade de inclusive preencher o centro da composição - só que o faz de tal modo que o indivíduo que figura nesse lugar, paradoxalmente, não o assume. Situar-se no centro não foi fruto de sua escolha, não foi o resultado do concurso de seu entendimento e sua vontade. Dir-se-ia que ele está ali involuntariamente, não fosse o fato de que atos involuntários supõem 
admitir a substância moral da vontade, artigo que parece estar em falta no mundo retratado por nosso pintor. ${ }^{16}$

Vai nesta direção outra pintura, "Comediantes italianos", de aproximadamente 1720. Percebe-se o mesmo rebaixamento narrativo que impregna "Pierrot Contente". A frivolidade do acontecimento torna-se condição para obter o efeito dramático da figura de Pierrot, pouco à vontade no centro da cena. O recurso à commedia dell'arte inverte o sentido clássico da composição unificada: deparamo-nos não com a ordenação do real da parte do indivíduo, mas com o caráter inexpressivo de Pierrot, em um drama que se curva para dentro dele mesmo, revelando uma interioridade psicológica com poucos antecedentes na pintura francesa. Desse modo, as mesmas escolhas compositivas operantes nas cenas de jogos e caça, assim como nas fêtes galantes, prestam-se à obtenção de uma eficácia dramática que desmente certa interpretação que reduziu Watteau ao pintor da "bombachadas".

Mas talvez o melhor contra-argumento a essa leitura da ausência de dramaticidade nos quadros de Watteau seja o célebre "Pierrot" ou "Gilles" (1718-1719). Novamente, a composição é segmentada: há dois planos bem distintos, cuja coexistência, não obtendo reconciliação, tensiona a cena em cujo centro se encontra Gilles. Ele a ocupa reforçando a ideia de seu isolamento - o qual, a rigor, não é só seu, é de todo indivíduo situado em uma temporalidade e uma ação destituídas de relevo. Nós também estamos ali, quando percebemos que ele nos olha.

\section{VI}

Já se vê, com base nessas poucas observações, por que somos levados a concluir que Watteau emancipou a representação do indivíduo da moldura clássica sob a qual ele havia feito sua primeira aparição na França. Em sua pintura, o drama do homem moderno vê-se destituído de qualquer elevação. Acenou-se aqui para o fato de que o nivelamento dos indivíduos efetuado pelo grupo ligado a Port-Royal (Pascal, La Rochefoucauld, Mme. de La Fayette, Racine) mantivera intacto o compromisso formal do classsicismo com o elevado ${ }^{17}$, a despeito da subversão completa do ideal moral da virtude clássica aí levada a cabo. Nesse contexto mais amplo, relacionado à evolução da cultura francesa em relação a formas modernas de representação, o significado de Watteau residiu, primeiramente, em realizar a transição do elevado para o baixo. Paradoxalmente, esse motivo fez que parte da crítica setecentista (Diderot sobretudo) terminasse por assimilá-lo ao cômico e às "bombachadas". Entretanto, como se quis aventar aqui, foi a investigação do cotidiano o que possibilitou a Watteau descortinar o indivíduo sem pertencimento, anônimo e condenado à sua própria interioridade - na melhor das hipóteses, alguém que desfruta de uma felicidade dominical e de uma paixão coreografada em pequenos gestos, divertimento e transitoriedade - um indivíduo que, 
embora sem aderência a qualquer filosofia da história, ou por isso mesmo, possui substância dramática própria.

\section{llustrações}

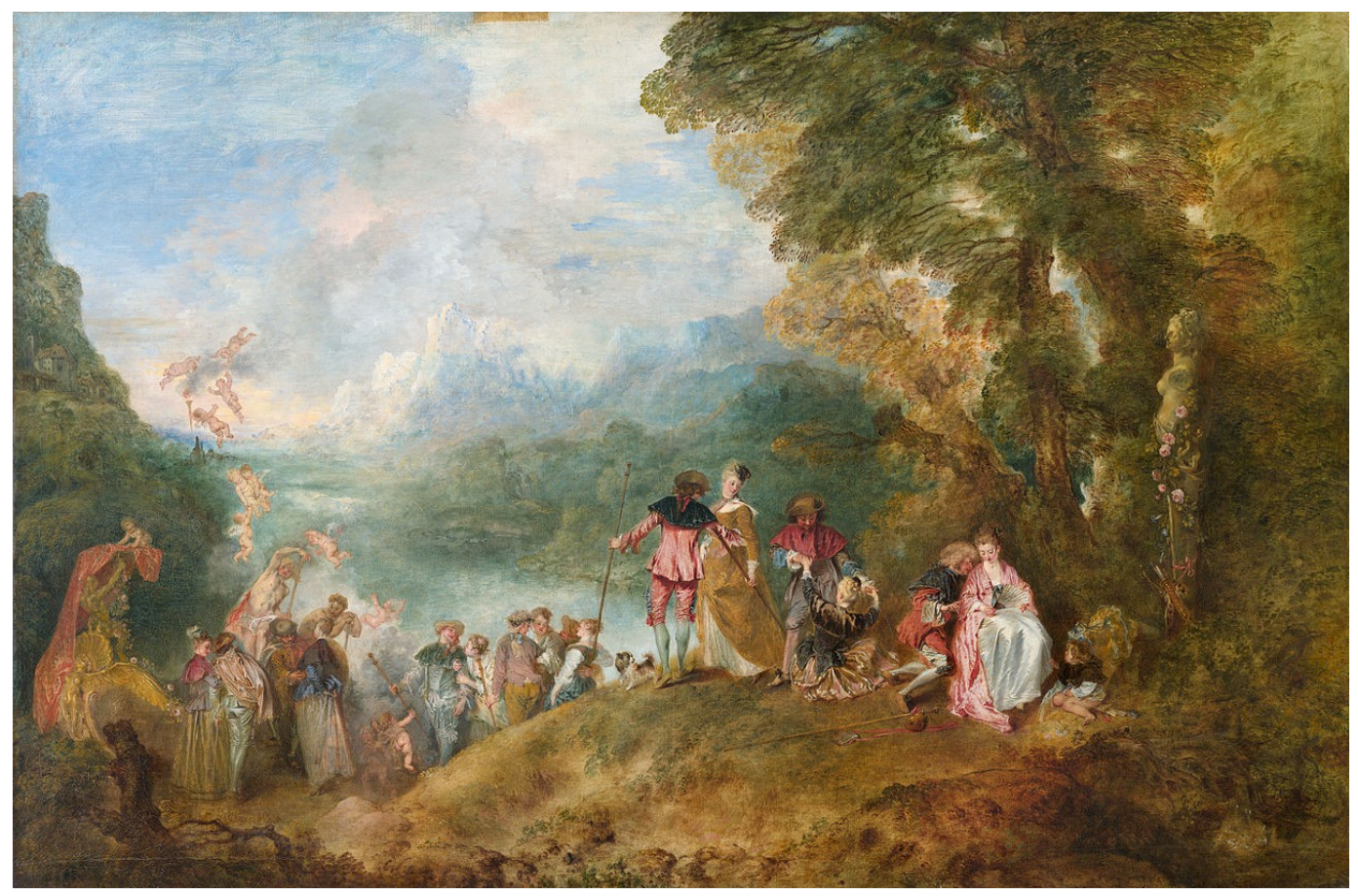

Watteau, A. Le pèlerinage à Chytère, 1717. Paris: Louvre. 


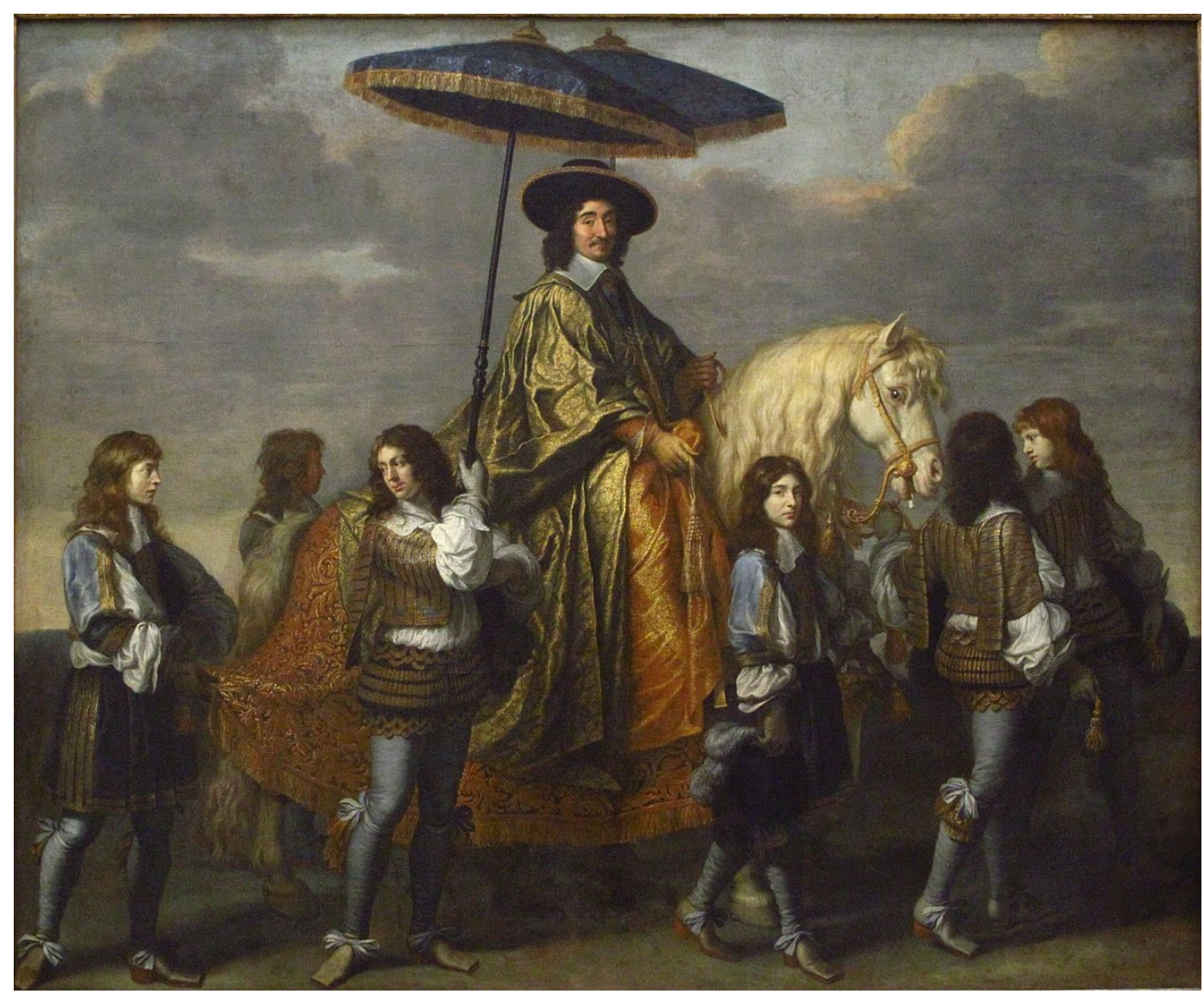

Le Brun, C. Chanceler Séguier à recepção de Luís XIV em Paris, 1655-1661. Paris: Louvre. 

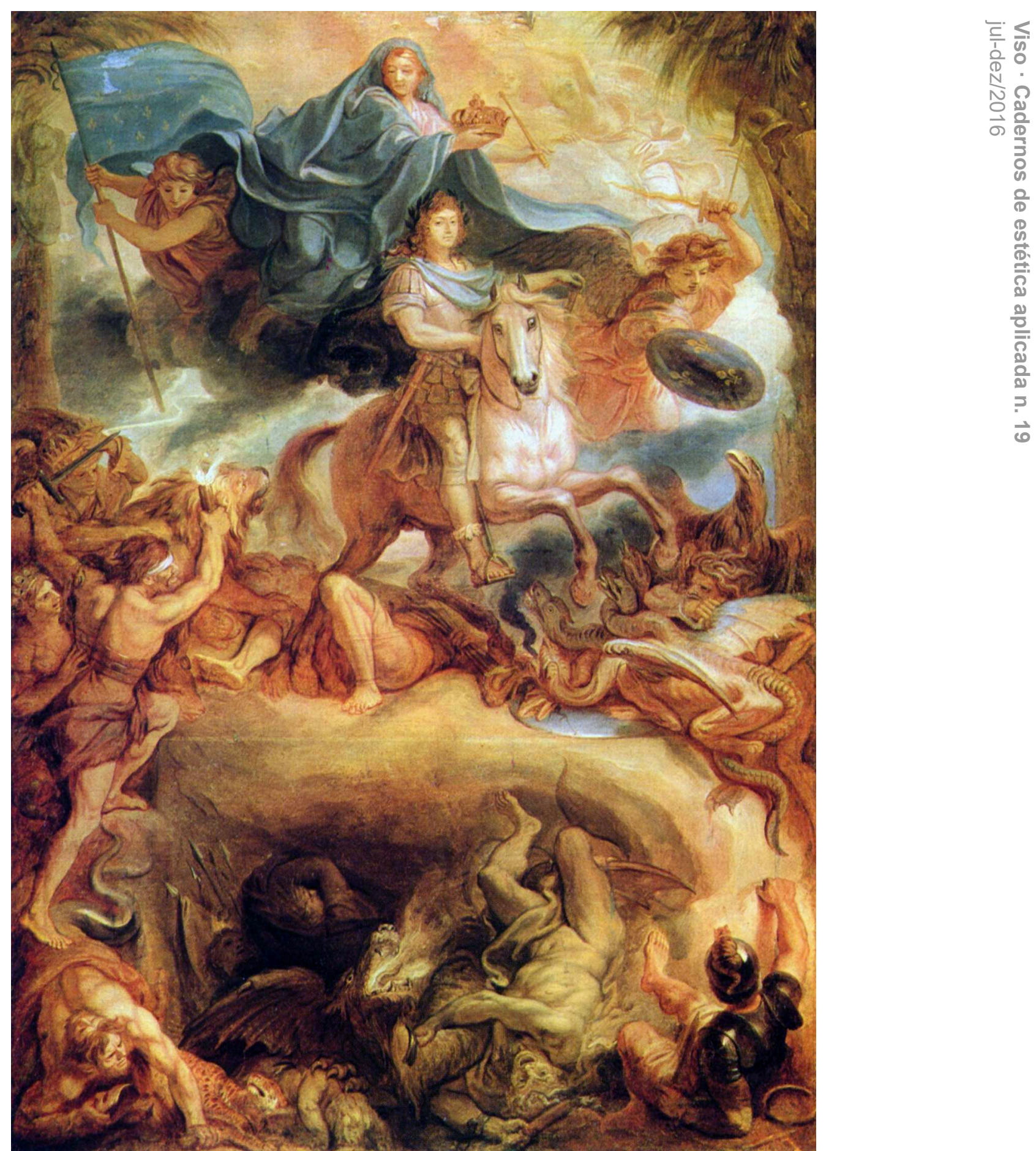

Le Brun, C. Apoteose de Luís XIV, 1677. Budapest: Szépmûvészeti Museum. 


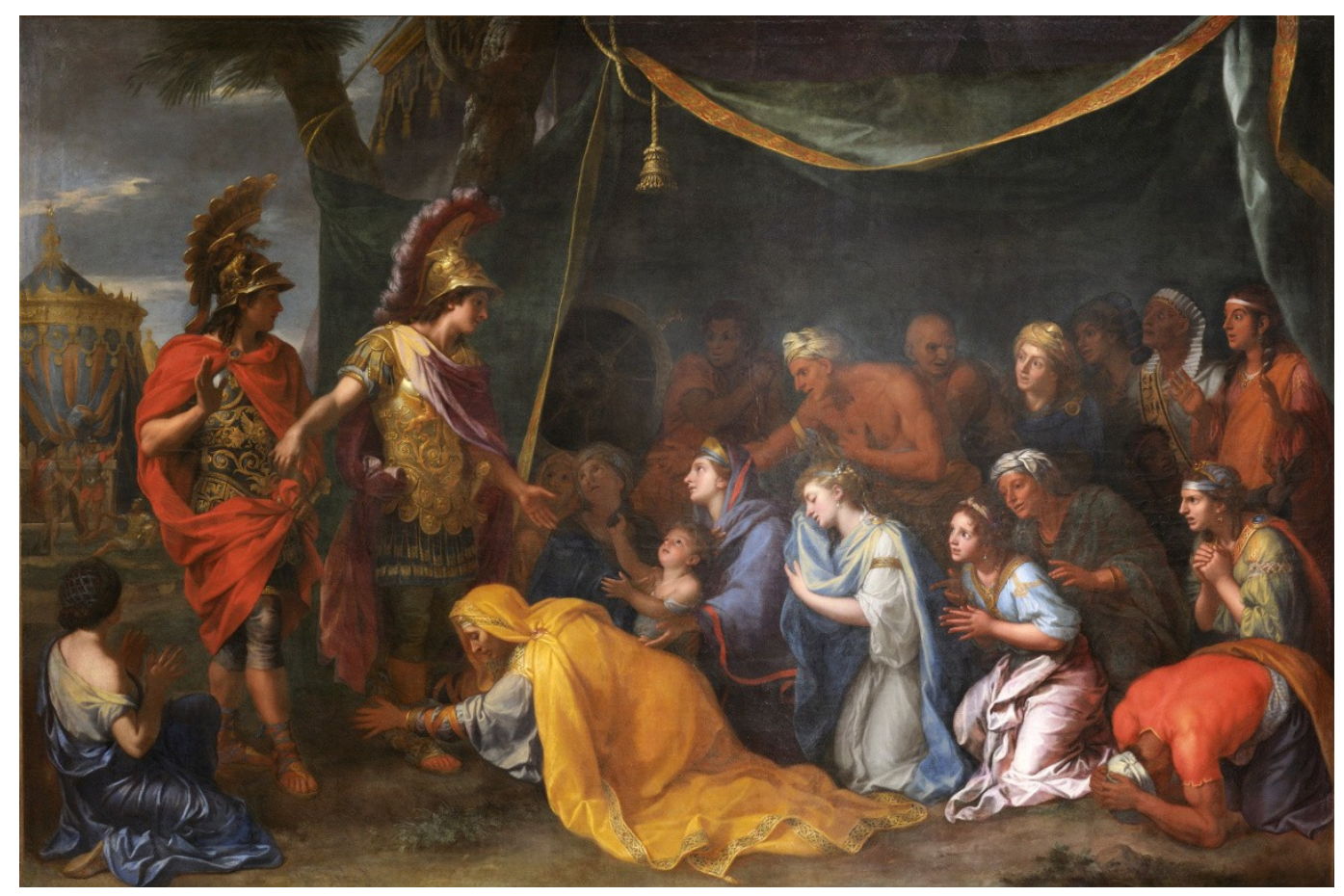

Le Brun, C. As rainhas da Pérsia diante de Alexandre, c. 1660. Versailles: usée National du Château.

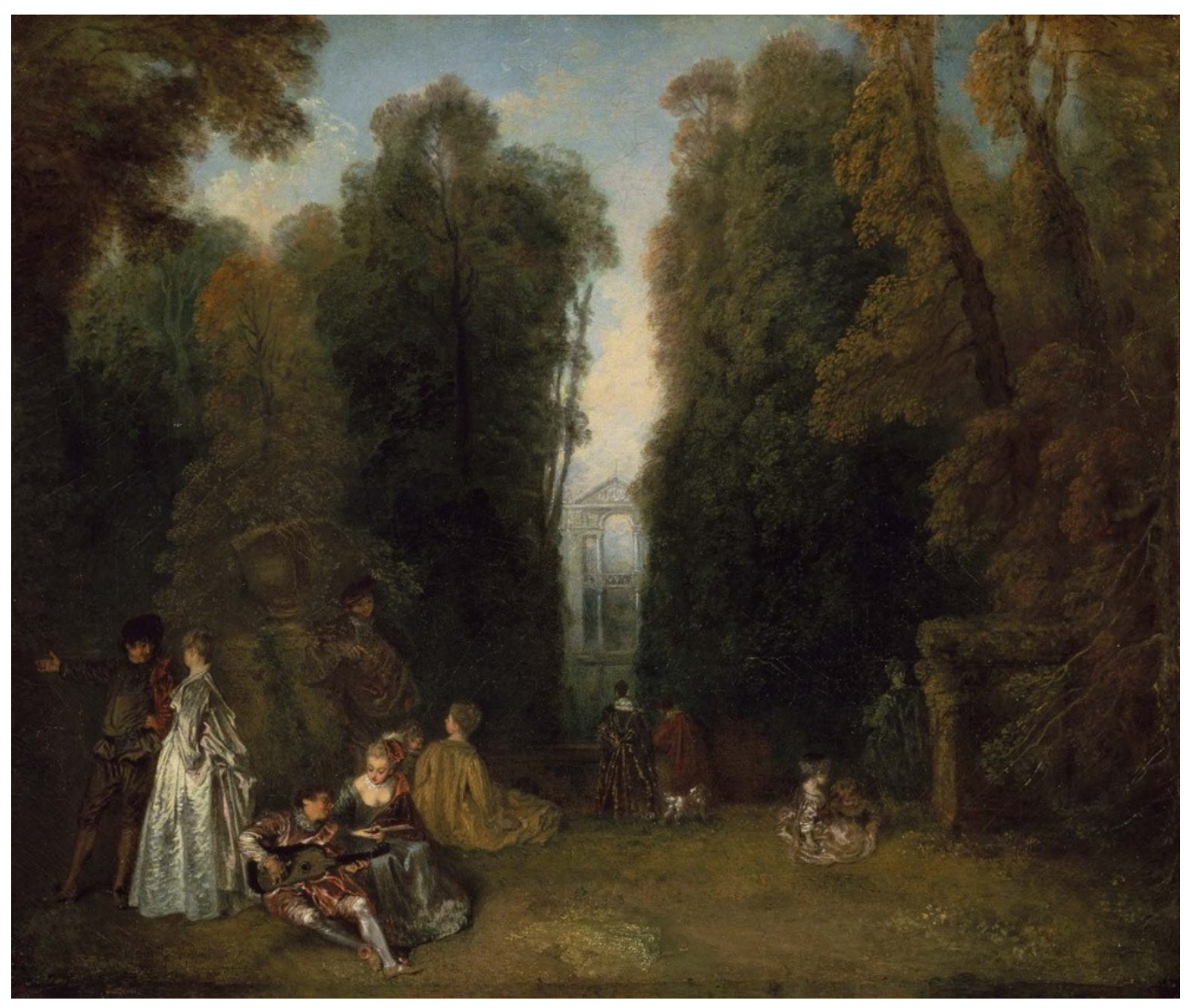

Watteau, A. La perspective, c.1717/1718. Boston (MA): Museum of Fine Arts.

Watteau e a irrupção da pintura moderna na França do século XVIII · Vinicius Figueiredo 


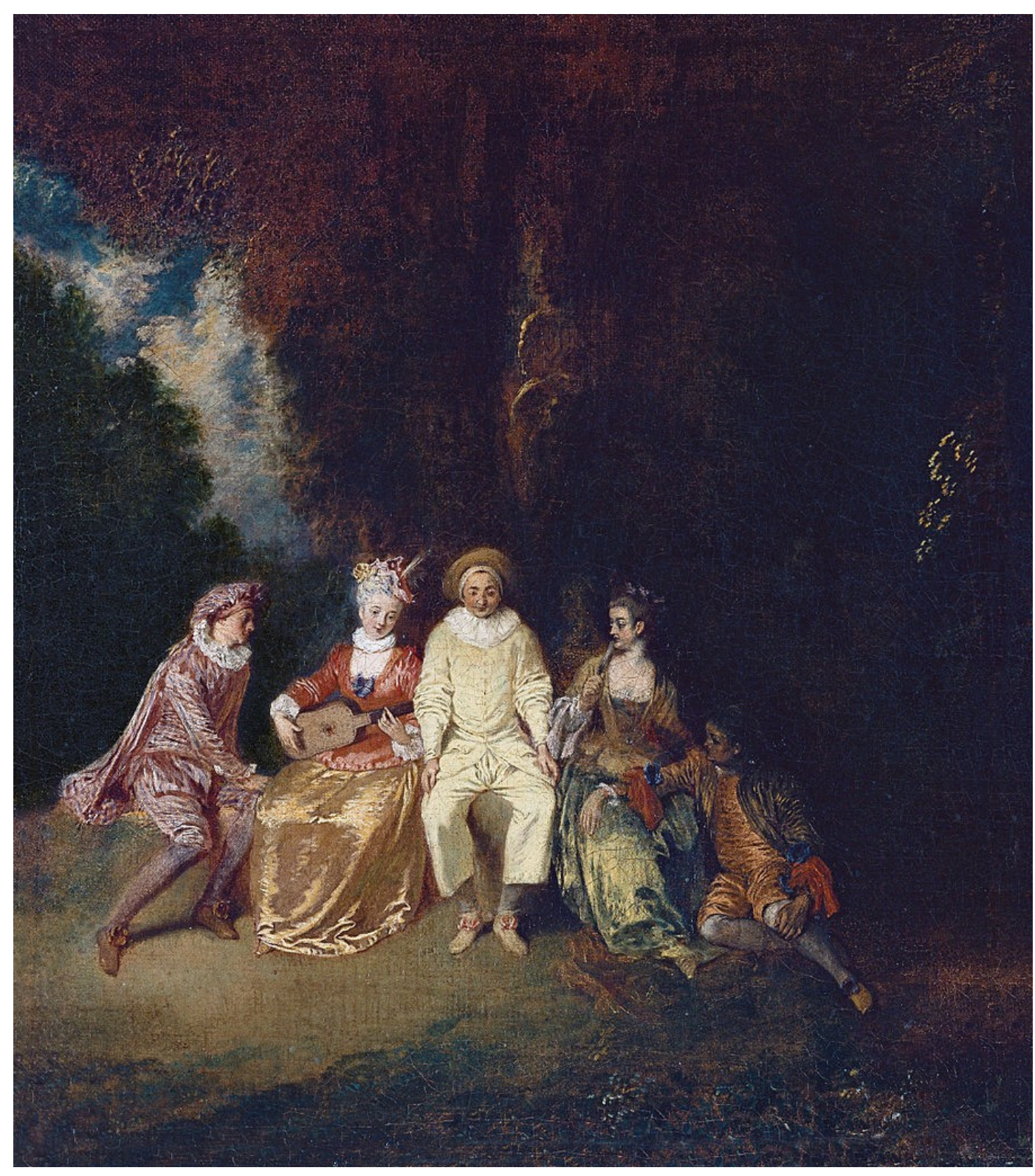

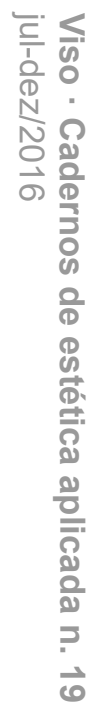

Watteau, A. Pierrot content, c. 1712. Madrid: Thyssen-Bornemisza. 


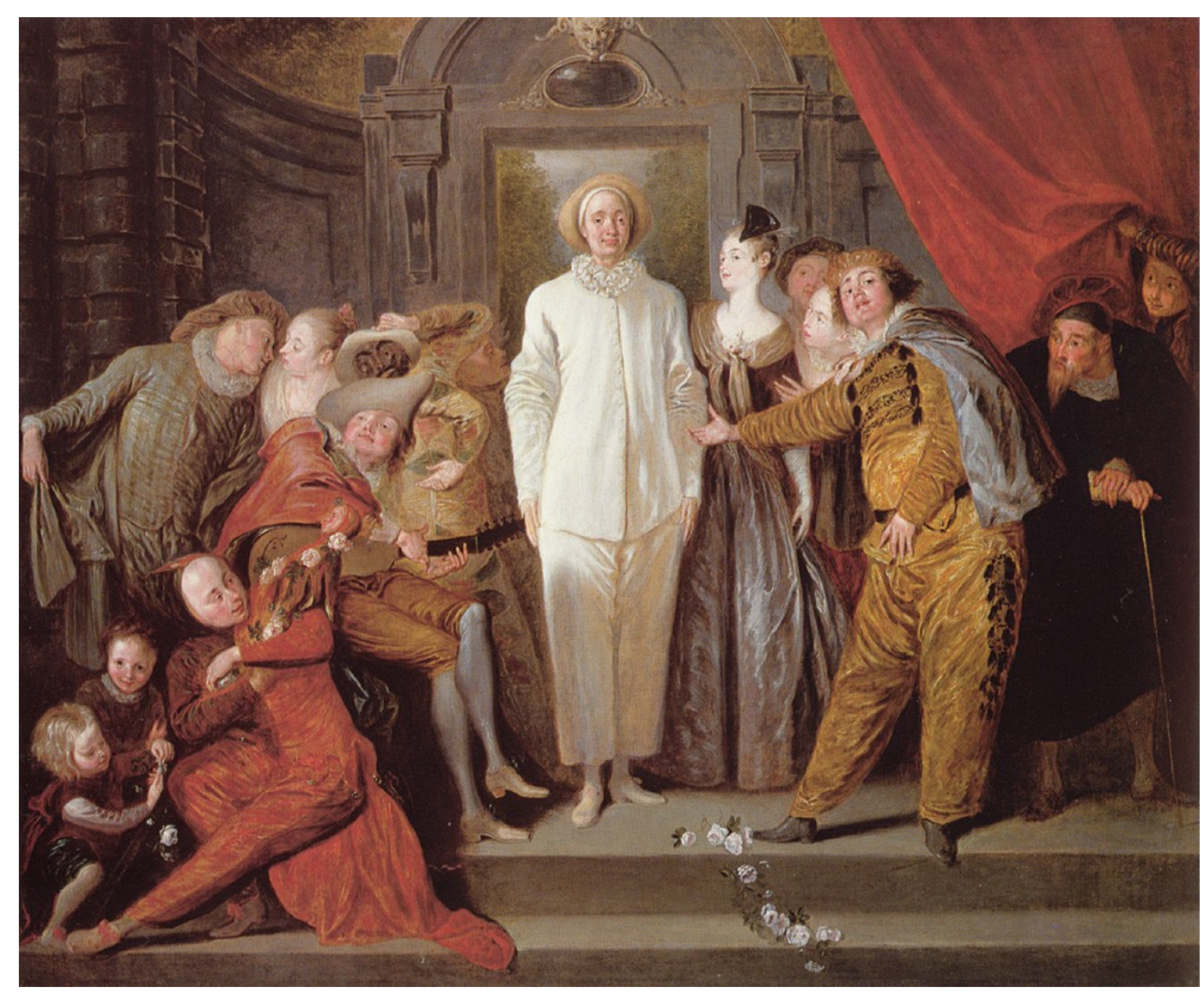

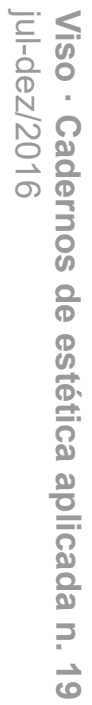

Watteau, A. Comédiens italiens, c. 1720. Washington, DC: National Gallery of Art. 


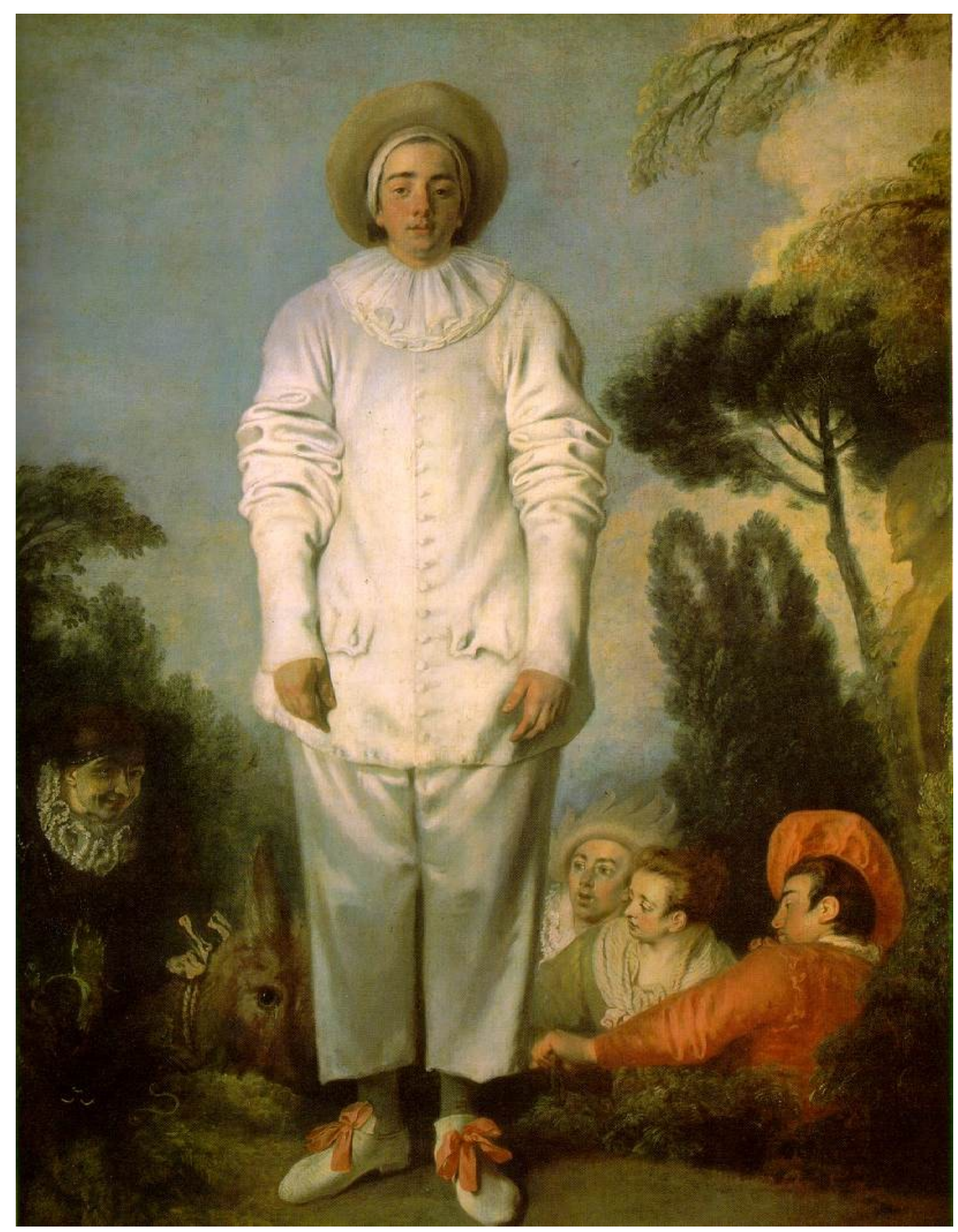

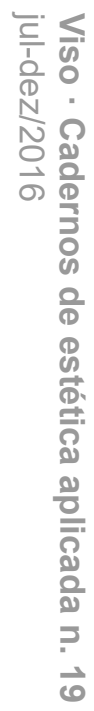

Watteau, A. Pierrot ou Gilles, 1718-1720. Paris: Louvre. 


\section{* Vinicius Figueiredo é professor do Departamento de Filosofia da UFPR.}

* Esse texto é parte provisória de um ensaio a ser publicado em 2017 sobre as relações entre poética e moral na França moderna. Publico-o na forma em que foi apresentado no $8^{\circ}$ Encontro do GT de Estética da ANPOF, realizado na Universidade Federal de Ouro Preto em maio de 2016. Agradeço a leitura e sugestões feitas por Virginia de Figueiredo e Vladimir Vieira.

${ }^{1}$ Cf. LEVEY, M. Pintura e escultura na França: 1700-1789. São Paulo: Cosac Naify, 1998, p. 40; GOMBRICH, E. História da arte. Rio de Janeiro: Guanabara ,1988, pp. 358-359.

${ }^{2}$ Como aponta Martin Eidelberg, o primeiro pintor a ser de fato recebido na Academia com esse título foi o célebre discípulo de Watteau, Jean-Baptiste Pater, em 31 de dezembro de 1728, designado, na ocasião, como "peintre dans le talent particulier des fêttes galantes". Ao próprio Watteau, entretanto, não foi atribuída designação alguma. "Quando foi recrutado [agrée] em 30 de julho de 1712, [Watteau] foi inscrito na lista da Academia apenas por seu nome, 'le sieur Antoine Watau', com a indicação de seu métier, 'Peintre' (por oposição a escultor, gravurista, etc.)" EIDELBERG, M. "Watteau, peintre de fêtes galantes". In: Watteau et la fête galante [Musée des Beaux-Arts de Valenciennes]. Paris: Éditions de la réunion des musées nationaux, 2004, pp. 17-27, aqui p. 19.

${ }^{3}$ Abade de Charnes apud ESCOLA, M. Nouvelles galantes du XVIlème siècle. Paris: Flammarion, 2004, p. 19.

4 "A considerar o conjunto desses 'pequenos romances', percebe-se que seu projeto não tem nada de inocente. De fato, tomando como objeto apenas as paixões dos grandes, reis e príncipes, as novelas operam uma verdadeira desconstrução da grande história, explicada por motivos pouco nobres, se não pelo triunfo da vaidade e da loucura" (DEMORIS, R. "Introduction". In: FÉLIBIEN, A. Entretiens sur les vies et les ouvrages des plus excellents peintres anciens et modernes - I e II. Paris: Les Belles Lettres, pp. 9-73, aqui p. 24).

5 "Às grandezas de estabelecimento, devemos respeito de estabelecimento, isto é, certas cerimônias exteriores que devem ser acompanhadas, segundo a razão, de um reconhecimento interior da justiça dessa ordem, mas que não nos fazem conceber nenhuma qualidade real naqueles que honramos dessa forma" (PASCAL, B. Pensamentos sobre a política. São Paulo: Martins Fontes, 1994, p. 84; grifo nosso).

${ }^{6}$ Cf. Ibidem.

${ }^{7}$ LA ROQUE, 1721, apud EIDELBERG, M. Op. cit., p. 21.

${ }^{8}$ FÉLIBIEN, A. [1667] 1725, V, pp. 310-311, apud BAYLE, C. "La peinture de genre en France au XVIIlème siècle". In: BAYLE, C. (org.), Au temps de Watteau, Chardin et Fragonard. Chefs-d' CEuvres de la peinture de genre en France. New Haven; Londres: Yale University, 2003, p. 4.

${ }^{9}$ PILLE, R. "Préface". In: Cours de peinture par principes [1708]. Paris: J. Thuillier, 1989.

10 Para a recepção da teoria aristotélica no contexto da difusão de Caravaggio, cf. ARIKHA. "Réflexion sur Poussin". In: Poussin: Lettres et propos sur l'art. Paris: Hermann, pp. 203-247, aqui p. 225.

${ }^{11}$ Cf. nota 2 supra.

12 "Uma Virgem que pintou e alguns outros temas de história dão a entender que ele poderia ter êxito nesse gênero. O gosto que seguiu é mais precisamente aquele das bombachadas e não convém ao sério; toda a indumentária é cômica, para o baile, e as cenas são ou teatrais ou campestres" (D'ARGENVILLE, D. Abregé de la vie des plus fameux peintres, avec leurs portraits gravés en taille-douce, les indications de leurs principaux ouvrages, quelques réflexions sur leurs caractères, et la maniere de connoître les desseins des grands maîtres. Par $M^{* * *}$ de l'Académie royale des sciences de Montpellier, 1745-1752, IV, 408, apud MARIETTE, P. J. Abecedario de Pierre Jean Mariette sur les Arts et les Artistes, Tome VI. Paris: J.B. Doumolin,1862, pp. 119-120). 
${ }^{13}$ CAYLUS apud GONCOURT, J. de; GONCOURT, E. L'art du dix-huitième siècle. v. 1: Watteau. Chardin. Boucher. Latour. Greuze. Les Saint-Aubin. Paris: Rapilly, 1873-1874, pp. 51-52. Em vista dessas observações, compreende-se que Michel Levey tenha afirmado que "Watteau poderia ter sido o grande gênio ignorado de sua época; esta teve a clarividência de lhe fazer jus, aclamandoo, quase adulando-o, na França e no estrangeiro, onde, de resto, ele foi possivelmente melhor compreendido" (LEVEY, M. Du Rococo à la Révolution [1966]. Tradução de M. Cohen. Paris: Thames \& Hudson, 1989, p. 55). De fato, e a despeito do prestígio de que gozou Watteau junto ao público e a colecionadores particulares importantes, como Crozat e Frederico II, público e crítica setecentistas, admirando-o ou condenando-o, parece ter visto nele essencialmente o criador das fêtes galantes e o pintor das "bombachadas".

14 "Muito frequentemente, as figuras parecem disseminadas no espaço sem que se possa discernir uma ordem subjacente. À aparente arbitrariedade da disposição das figuras se acresce a dificuldade para o espectador em identificá-las" (JOLLET, E. Watteau: Les fêtes galantes. Paris: Herscher, 1994, p. 8).

${ }^{15}$ LEVEY, M. Op. cit., p. 40.

${ }^{16}$ Pode-se, já se vê, sustentar que há uma retomada de elementos pascalianos na poética de Watteau. Tudo se passa como se Pierrot ilustrasse, mas sob uma nova roupagem, este fragmento de Pascal sobre a ausência de sentido da vida: "Quando contemplo a pequena duração da minha vida aborvida na eternidade precedente e seguinte - memoria hospitis unitus diei praetereuntis -, o pequeno espaço que preencho e mesmo que vejo abismado na infinita imensidão dos espaços que ignoro e que me ignoram, apavoro-me e admiro-me por me ver aqui e não lá, pois não existe razão por que aqui e não lá, por que agora e não então. Quem me colocou aqui ? Pela ordem e pela intervenção de quem este lugar e este tempo foi destinado a mim?" (PASCAL, B. Pensamentos. Tradução de M. Laranjeira. São Paulo: Martins Fontes, 2001, LA 68/Br. 205).

${ }^{17}$ Esse ponto é largamente desenvolvido no segundo ensaio do anunciado livro, que investiga a ruptura de Port-Royal com o ideário clássico, representado pelo herói de Corneille e pelo virtuoso cartesiano. 